\title{
Metabolism of Adrenal Cholesterol in Man
}

\section{IN VIVO STUDIES}

\author{
Abraham Borkowski, Claude Delcroix, and Sam Levin \\ From the Service of Medicine and Clinical Investigation, Institut Jules Bordet, \\ Centre Anti-cancéreux de l'Université Libre de Bruxelles, and Central \\ Laboratory of Nuclear Medicine, Brussels, Belgium
}

\begin{abstract}
A B S T R A C T The kinetics of plasma and adrenal cholesteral equilibration were analyzed in patients undergoing bilateral adrenalectomy for generalized mammary carcinoma. A biological model is proposed to help in the understanding of adrenal cholesterol physiology. It comprises two intracellular compartments: (1) A compartment of free adrenal cholesterol which is small (of the order of $17 \mathrm{mg}$ ) but turns over very fast; it is renewed approximately 8 times per day: 3 times by the inflow of free plasma cholesterol, and 5 times by the hydrolysis of esterified adrenal cholesterol, the contribution of adrenal cholesterol synthesis appearing to be relatively small. (2) A compartment of esterified adrenal cholesterol which is 20 times larger; it is constantly renewed by in situ esterification and hydrolysis with a daily fractional turnover rate of the order of 0.25 . The direct and selective accumulation of plasma cholesteryl esters is practically absent. Only free adrenal cholesterol returns to plasma, mostly after conversion into steroid "hormones."

However small the synthesis of adrenal cholesterol may be, it seems more important in the zona "reticularis." On the other hand, the inflow of plasma cholesterol and the turnover of the free adrenal compartment tend to be faster in the zona "fasciculata." The equilibration of plasma and adrenal cholesterol can proceed unmodified under conditions of ACTH suppression.

In one patient with Cushing's disease the size of the two adrenal compartments was clearly increased but their equilibration with plasma cholesterol proceeded normally. In another patient the kinetics of hydrocortisone corresponded to those of free adrenal cholesterol in the control studies.
\end{abstract}

Received for publication 9 November 1971 and in revised form 15 February 1972.

\section{INTRODUCTION}

The work reported here is a kinetic in vivo analysis of the equilibration of free and esterified plasma cholesterol with free and esterified adrenal cholesterol in patients undergoing bilateral adrenalectomy for generalized mammary carcinoma and in patients with Cushing's disease. It represents an attempt to construe a biological model which would account for the cortical gradient of concentration (1), the widespread intracellular distribution $(2)$, the chemical $(2,3)$ and functional (4-6) heterogeneities of adrenal cholesterol in man and for the possible regulatory role of ACTH.

Such a model might help in the understanding of adrenal cholesterol physiology with regard to the quantitative importance of local cholesterol synthesis (7), of plasma cholesterol inflow (8), and of adrenal cholesterol outflow either as unmodified cholesterol or in the form of steroid hormones. The model might also provide some information concerning the origin, fate and turnover of esterified adrenal cholesterol which constitutes a large intracellular pool and has a characteristic fatty acid pattern which is distinct from that of esterified plasma cholesterol $(3,9)$. Finally, the model might shed some light on the regulatory mechanisms which control free adrenal cholesterol concentration and maintain it within remarkably narrow limits of variation (10).

As far as ACTH is concerned it is known that this polypeptide accelerates the conversion of adrenal cholesterol into steroid hormones (11); however, its influence on the other parameters of adrenal cholesterol physiology remains to be elucidated. Furthermore, since in the absence of ACTH the adrenal cortex stops producing adrenal steroid hormones and consequently ceases to exert its specialized functions, a study of adrenal cholesterol metabolism under conditions of

1664 The Journal of Clinical Investigation Volume 51 July 1972 


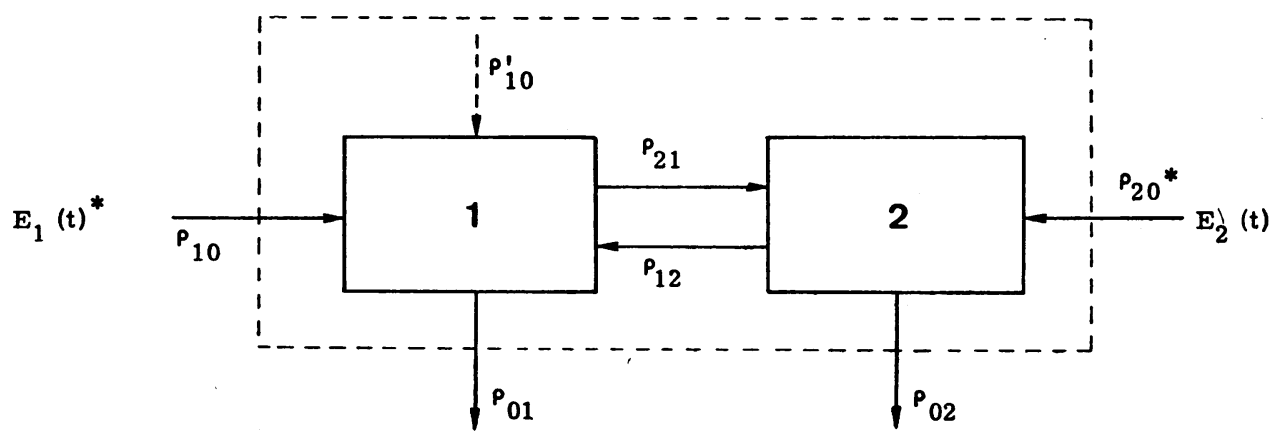

Figure 1 Kinetic model of adrenal cholesterol metabolism.

ACTH suppression might provide some information relevant to the physiology and pathology of cholesterol equilibration and accumulation in tissues other than the adrenal cortex $(12,13)$.

\section{METHODS}

Search for a biological model and parameters to account for the equilibration of plasma and adrenal cholesterol in control studies. This represents a new theoretical treatment of data previously obtained in 24 patients undergoing bilateral adrenalectomy for generalized mammary carcinoma (2). Cholesterol-4-14C $\mathrm{C}$ was administered i.v. during a $3 \mathrm{hr}$ infusion, this infusion taking place within the 7 days preceding surgery. The plasma samples were collected $24 \mathrm{hr}$ after the end of the tracer infusion, shortly before the adrenalectomy and at various other time intervals. The specific activities of free and esterified plasma cholesterol were compared with those of free and esterified adrenal cholesterol, all the experimental data being normalized to a same specific activity of total plasma cholesterol at $24 \mathrm{hr}$.

Adrenal cholesterol was fractionated according to its zonal distribution. The adrenal cortex was sliced into two or three layers, the capsule and its adhering cortical tissue being discarded: the inner half or third, which included the zona reticularis, was named somewhat arbitrarily "reticularis" despite its unavoidable contamination by the zona fasciculata, and the outer half or the outer two-thirds were named "fasciculata" although they did not include the whole zona fasciculata.

Free and esterified cholesterol were separated from each other by thin-layer chromatography (14) and their specific activities were determined as previously described by the method of Sperry and Webb (15) and by liquid scintillation counting.

Our nomenclature for tracer kinetics is that of Brownell, Berman, and Robertson (16). The biological model chosen for the kinetic analysis of the experimental data is symbolized as shown in Fig. 1. According to this model, adrenal cholesterol is investigated separately in the zona reticularis and in the zona fasciculata but is viewed in each zone as a subsystem of two homogeneous states, 1 and 2, representing, respectively, the free and the esterified forms. Compartment 1, i.e. free adrenal cholesterol, is renewed by an inflow of free plasma cholesterol: $E_{1}(t)$, the symbol for the corresponding flow rate being $\rho_{10}$; compartment 1 is also renewed by a local synthesis, $\rho_{10}^{\prime}$, and by the hydrolysis of esterified adrenal cholesterol, $\rho_{12}$; free adrenal cholesterol returns into the general circulation directly, unmodified or converted into steroid hormones, $\rho_{01}$; and indirectly, after a previous esterification, poe. Compartment 2, i.e. esterified adrenal cholesterol, results from a local esterification of free adrenal cholesterol, $\rho_{21}$, but also perhaps from the accumulation of some plasma cholesteryl esters, $E_{2}(t)$, the flow of which is expressed by the symbol $\rho_{20}$; esterified adrenal cholesterol can be hydrolyzed to free adrenal cholesterol and return to compartment $1, \rho_{12}$; but a direct secretion into the blood, $\rho_{02}$, as unmodified adrenal cholesteryl esters, after a separate hydrolysis or/and after a separate conversion into steroid hormones cannot be excluded.

This model imposes very little restraint since it does not prejudge the size of the compartments, their origin or their destination except for the entry of $E_{2}(t)$ in the adrenal subsystem through compartment 2 . Although the elaboration of a more rigorous model should rely on the delays in the curves of cholesterol incorporation into its adrenal states and into the steroid hormones we are justified (see Appendix I) to use a first order model. The mathematical formulation is then:

$$
\begin{aligned}
\mid \dot{\chi} /=f(\chi, \mathrm{E}, \mathrm{P}, \mathrm{t})=/ / \mathrm{A}(\mathrm{p}) / / & / \mathrm{x}(\mathrm{t}) / \\
& +/ / \mathrm{B}(\mathrm{p}) / / \cdot / \mathrm{E}(\mathrm{t}) /
\end{aligned}
$$

in which $/ \chi /$ is the state vector of the system, $/ \dot{\chi} /$ is its derivative; //A (p)// is the matrix which characterizes the exchanges between the states of the adrenal subsystem as well as their eventual outputs; //B(p)// is the matrix which characterizes the inputs; and $/ E(t) /$ is the vector describing the precursors of the subsystem.

According to our model, if $\mathrm{Sj}(\mathrm{j}: 1$ or 2 ) symbolizes the sizes of the pools and $\rho_{\mathrm{ij}}$ the flow rates from state $\mathrm{j}$ to state $\mathrm{i}$, the matrices can be written:

$$
/ / \mathrm{A}(\mathrm{p}) / /=\left|\begin{array}{cc}
-\frac{\rho_{01}+\rho_{21}}{\mathrm{~S}_{1}} & \frac{\rho_{12}}{\mathrm{~S}_{1}} \\
\frac{\rho_{21}}{\mathrm{~S}_{2}} & -\frac{\rho_{12}+\rho_{02}}{\mathrm{~S}_{2}}
\end{array}\right|
$$

and

$$
/ / \mathrm{B}(\mathrm{p}) / /=\left|\begin{array}{cc}
\frac{\rho_{10}}{\mathrm{~S}_{1}} & 0 \\
0 & \frac{\rho_{20}}{\mathrm{~S}_{2}}
\end{array}\right|
$$

As for the input vector, $/ E(t) /$, it comprises: 
$E_{1}(t)$, specific activities of free plasma cholesterol; and $E_{2}(t)$, specific activities of esterified plasma cholesterol. Since according to our model there may be a synthesis of cholesterol (or a dilution by cold molecules) within compartment 1 and not within compartment 2 it can be added that:

$$
\frac{\rho_{01}+\rho_{21}}{\mathrm{~S}_{1}} \geqslant \frac{\rho_{10}}{\mathrm{~S}_{1}}+\frac{\rho_{12}}{\mathrm{~S}_{1}}
$$

and

$$
\frac{\rho_{20}}{\mathrm{~S}_{2}}+\frac{\rho_{21}}{\mathrm{~S}_{2}}-\frac{\rho_{12}+\rho_{02}}{\mathrm{~S}_{2}}=0 .
$$

It is obvious that equations 1 and 2 make it possible to reduce the number of independent parameters to five; two of them are turnover rates, i.e. fraction of the tracee that leaves a compartment per unit time $\left(\sum_{\mathrm{i}} \frac{\rho_{\mathrm{ij}}}{\mathrm{S}_{\mathrm{j}}}\right):(a)\left(\rho_{01}+\rho_{21}\right) / \mathrm{S}_{1}$ $=\mathrm{k}_{11}$, turnover rate of compartment $1 ;$ and $(b)\left(\rho_{12}+\rho_{02} / \mathrm{S}_{2}\right.$ $=\mathrm{k}_{22}$, turnover rate of compartment 2 ; the three other independent parameters are what we call "inflow turnover rates," i.e. fraction of the tracee that enters a compartment per unit time from a given direction $\left(\frac{\rho_{\mathrm{ij}}}{\mathrm{S}_{\mathrm{i}}}\right):(c) \rho_{10} / \mathrm{S}_{1}=\mathrm{p}_{10}$, the inflow turnover rate of compartment 1 by free plasma cholesterol; (d) $\rho_{12} / \mathrm{S}_{1}=\mathrm{p}_{12}$, the inflow turnover rate of compartment 1 by esterified adrenal cholesterol hydrolysis; $(e) \rho_{21} / S_{2}=p_{21}$, the inflow turnover rate of compartment 2 by free adrenal cholesterol esterification.

The importance of cholesterol synthesis into compartment 1 can be obtained indirectly from the difference between the outflows and inflows just described:

$$
\frac{\rho_{10}^{\prime}}{\mathrm{S}_{1}}=\frac{\rho_{01}+\rho_{21}}{\mathrm{~S}_{1}}-\frac{\rho_{10}}{\mathrm{~S}_{1}}-\frac{\rho_{12}}{\mathrm{~S}_{1}} .
$$

The importance of the inflow of esterified plasma cholesterol into compartment 2 can be obtained indirectly in a similar fashion:

$$
\frac{\rho_{20}}{\mathrm{~S}_{2}}=\frac{\rho_{12}+\rho_{02}}{\mathrm{~S}_{2}}-\frac{\rho_{21}}{\mathrm{~S}_{2}}
$$

The input curves of free and esterified plasma cholesterol specific activities were simulated as function generators from the experimental data by a linear increase during the first $9 \mathrm{hr}$ and by a multiexponential function thereafter (see Appendix II).

The analytical form of the free and esterified adrenal cholesterol curves was calculated from the plasma cholesterol curves by a Laplace Transform and its inverse. The adrenal cholesterol curves, which are nonlinear functions of the five parameters mentioned above, were fitted to the experimental data with the help of a computer by the method of the gradient combined with a Monte Carlo sounding $(17,18)$ in order to minimize the sums of the squares of the relative deviations. Identical parameters were found when, for the purpose of verification, the data and the model were investigated through the SAAM 23 program (19). The SAAM 23 program provided in addition the standard deviations of the parameters. Finally, the sensitivity of the model to the various parameters was explored with the help of an analog computer (20) (see Appendixes II and III).

Studies under conditions of ACTH suppressin. The specific activities of plasma and adrenal cholesterol after cholesterol-4- ${ }^{14} \mathrm{C}$ administration were measured and analyzed as in the control studies, but were obtained in 12 patients taking suppressive doses of glucocorticosteroid hormones. 10 of these patients took $1 \mathrm{mg}$ of dexamethasone orally every $6 \mathrm{hr}$ from 1 to 3 days before the tracer administration until the adrenalectomy. Two other patients, because of hypercalcemia or thrombocytopenia, took $60 \mathrm{mg}$ of prednisolone orally per day during the 2 wk immediately preceding the adrenalectomy and were operated, respectively, 2 days and 12.5 days after the tracer administration.

Studies in Cushing's disease. Two patients with Cushing's disease were investigated in a similar fashion.

In one patient, $8 \mu \mathrm{Ci}$ of cholesterol- $4-{ }^{14} \mathrm{C}$ were administered $24 \mathrm{hr}$ before adrenalectomy. The specific activities of free and esterified adrenal cholesterol were compared with those of corresponding free, esterified, and total plasma cholesterol. In addition, the various adrenal cholesteryl esters were fractionated and separated from each other as previously described.

The other patient was given $25 \mu \mathrm{Ci}$ of cholesterol-4 ${ }^{14} \mathrm{C}$ and the specific activities of tetrahydrocortisol (THF) and tetrahydrocortisone (THE) in the urines, i.e. actually, with some delay, the specific activities of cortisol secreted from the adrenal cortex, were followed in time in order to investigate the pool of adrenal cholesterol which serves as precursor to the adrenal steroid hormones. The 24-hr urines were collected, hydrolyzed and extracted as described by Drucker, Sfikakis, Borkowski, and Christy (21). The extracts were chromatographed successively in the systems of Burton, Zaffaroni, and Keutmann (22), Bush 5 (23), and eventually $E_{4}$ of Eberlein and Bongiovanni (24). The specific activities of THE and THF were determined by a Porter and Silber colorimetry (21) and by liquid scintillation counting; they were found to be identical to each other within $5 \%$ limits. They were expressed in dpm per milligram of cholesterol in order to be compared with the specific activities of plasma cholesterol and consequently with those of adrenal cholesterol already obtained in the previous studies on plasma and adrenal cholesterol equilibration; after correction for molecular weight differences the specific activities of THE and THF were thus normalized in the same fashion as those of plasma and adrenal cholesterol. Actually, in order to identify the urinary metabolites of hydrocortisone with plasma hydrocortisone and with adrenal cholesterol, the specific activities of these metabolites should also be displaced several hours ahead; however, since the delay which elapses between the conversion of adrenal cholesterol into steroid hormones and the excretion of THE and THF in the urines is inferior to $24 \mathrm{hr}$, the curve of the hydrocortisone metabolites in urine is still a fairly good reflexion of the corresponding curve of adrenal cortisol and of its adrenal cholesterol precursor.

\section{RESULTS}

Parameters of adrenal cholesterol in control studies. The parameters are given in Table I with their standard deviations whereas Fig. 2 illustrates in the zona "fasciculata" how the newly computed curves fit the previous experimental data; Fig. 2 shows furthermore the evolution in time of free and esterified adrenal cholesterol specific activities in comparison to the specific activities of free and esterified plasma cholesterol. On 


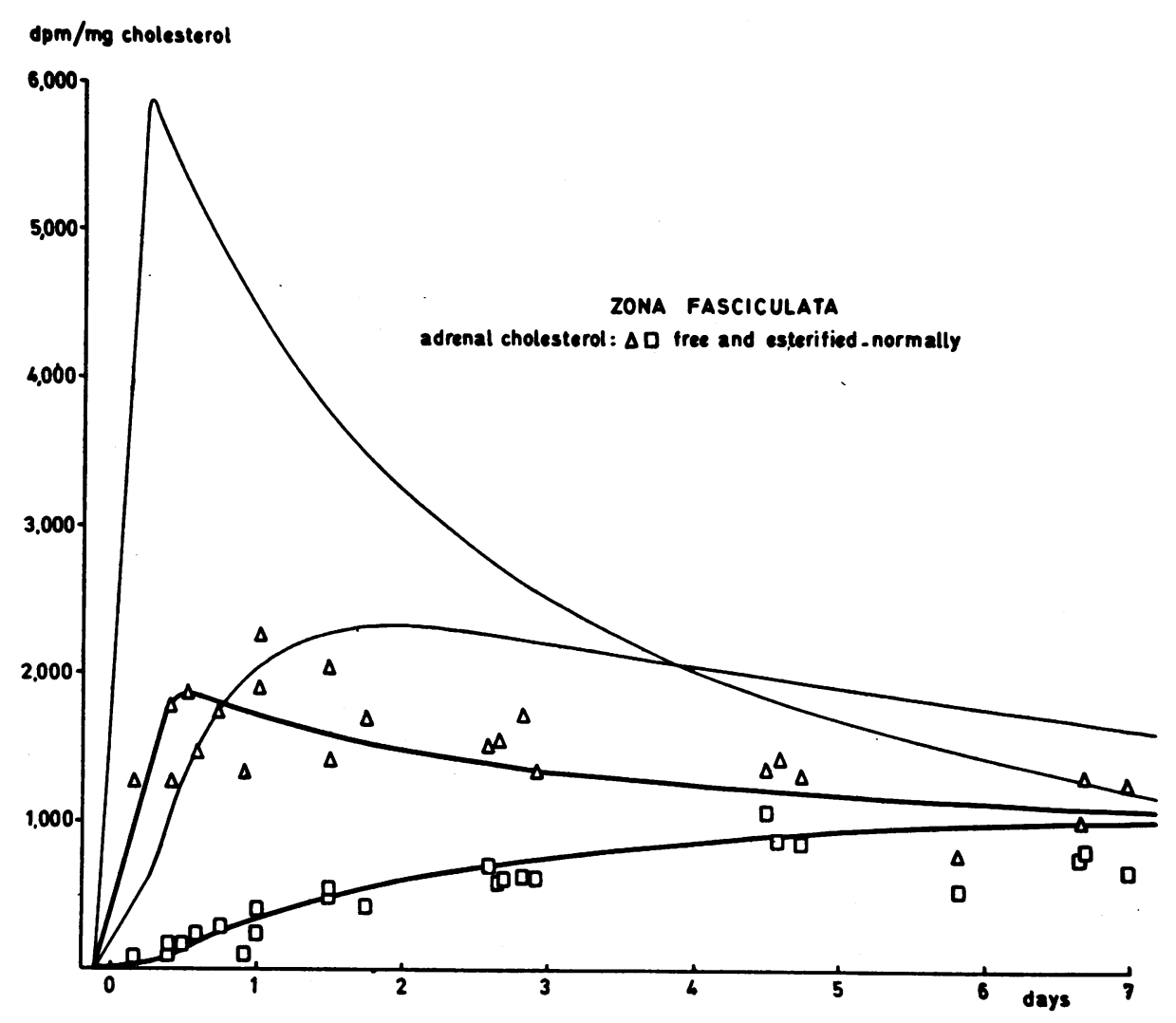

FIGURe 2 Equilibration of plasma and adrenal cholesterol under control conditions. The thin-lined curves represent the mean specific activities of plasma cholesterol, respectively, free (above) and esterified (below). The thick-lined curves are those which are computed for the specific activities of free (above) and esterified (below) adrenal cholesterol within the frame of the model described in Methods. The symbols represent the individual experimental points of adrenal cholesterol.

the other hand, Fig. 5 allows a comparison of the computed curves in the two adrenal zones.

According to our parameters free adrenal cholesterol appears to be a very dynamic compartment which turns over approximately eight times per day (k11 or ( $\rho_{01}+$ $\left.\left.\rho_{21}\right) / S_{1} \approx 8\right):$ on the average it is renewed three times per day by the inflow of free plasma cholesterol (p1o or $\rho_{10} / S_{1} \approx 3$ ) and five times per day by the hydrolysis of esterified adrenal cholesterol ( $p_{12}$ or $\rho_{12} / \mathrm{S}_{1} \approx 5$ ). The importance of the local synthesis $\left(p_{10}^{\prime}\right.$ or $\left.\rho_{10}^{\prime} / S_{1}\right)$ is found by the difference: $p_{10}^{\prime}=k_{11}-\left(p_{10}+p_{12}\right)$ and seems to be relatively small if not negligible: $p^{\prime}{ }_{10}=0$ to 0.3 .

Esterified adrenal cholesterol which is 20 times more abundant than free adrenal cholesterol (2), turns over much much slowly; however esterified adrenal cholesterol is certainly not a resting, metabolically inactive compartment since, according to our data, its daily turnover rate $\left(\mathrm{k}_{22}\right)$ is of the order of 0.24 ; in other words, esterified adrenal cholesterol appears to be re-
TABLE I

Parameters of Adrenal Cholesterol (day $\left.{ }^{-1}\right)^{*}$

\begin{tabular}{cccl}
\hline & Fasciculata & Reticularis & Means \\
\hline Pool 1 & & & \\
$\mathrm{k}_{11}=\frac{\rho_{01}+\rho_{21}}{\mathrm{~S}_{1}}$ & $10.24 \pm 1.72$ & $5.56 \pm 4.02$ & $\approx 8$ \\
$\mathrm{p}_{10}=\frac{\rho_{10}}{\mathrm{~S}_{1}}$ & $3.34 \pm 0.64$ & $2.38 \pm 1.57$ & $\approx 3$ \\
$\mathrm{p}_{12}=\frac{\rho_{12}}{\mathrm{~S}_{1}}$ & $6.88 \pm 0.19$ & $2.90 \pm 1.70$ & $\approx 5$ \\
$\mathrm{Pool} 2$ & & & \\
$\mathrm{k}_{22}=\frac{\rho_{12}+\rho_{02}}{\mathrm{~S}_{2}}$ & $0.23 \pm 0.19$ & $0.25 \pm 0.47$ & $\approx 0.24$ \\
$\mathrm{p}_{21}=\frac{\rho_{21}}{\mathrm{~S}_{2}}$ & $0.23 \pm 0.18$ & $0.25 \pm 0.47$ & $\approx 0.24$ \\
\hline
\end{tabular}

* Values \pm SD. 
newed every 4 or 5 days. Interestingly enough, the daily turnover rate of esterified adrenal cholesterol $\left(\mathrm{k}_{22}\right)$ is absolutely equal to its inflow turnover rate from one single source of supply, the in situ esterification of free adrenal cholesterol (px); in other words esterified adrenal cholesterol appears to be exclusively supplied by this in situ esterification and there is no direct accumulation of plasma cholesteryl esters ( $p_{20}$ or $\rho_{20} / \mathrm{S}_{2}$ $=0$ ).

If the synthesis of adrenal cholesterol is small and if there is no direct accumulation of plasma cholesteryl esters in the adrenal cortex, adrenal cholesterol must be provided essentially by the inflow of free plasma cholesterol into compartment 1 . This inflow can be calculated approximately from $\mathrm{p}_{10}$ and $S_{1}$, i.e., from the inflow turnover rate of free adrenal cholesterol by free plasma cholesterol and from the size of the free adrenal cholesterol compartment in the zonas fasciculata plus reticularis of the two adrenal glands. We have measured $S_{1}$ in nine pairs of adrenal glands and found a mean value of $17 \mathrm{mg}$ (SD $8 \mathrm{mg}$ ); since the mean p1o is of the order of 3 , the daily inflow of plasma cholesterol should amount to $3 \times 17$ and be of the order of $50 \mathrm{mg} /$ day.

With regard to the parameters $p_{12}$ and $p_{21}$ which define the intracellular exchanges taking place between free and esterified adrenal cholesterol, it is striking that their mean values, when compared with each other, are in a ratio of 20 to 1 : this is precisely the mean ratio of the sizes of the two intracellular compartments themselves, since as mentioned before, esterified adrenal cholesterol is 20 times more abundant than free adrenal cholesterol. The amount of cholesterol which leaves compartment 2 for compartment 1 ( $\left.\rho_{12}\right)$ must therefore be quite similar to that which enters compartment 2 from compartment $1\left(\rho_{21}\right)$. As a consequence, since esterified adrenal cholesterol results essentially from free adrenal cholesterol esterification, it must leave inversely by hydrolysis and return at first into the compartment of free adrenal cholesterol; in other words, $\rho_{02}$, i.e., a direct outflow or secretion of esterified adrenal cholesterol into the general circula- tion, in unmodified or in metabolized form, must be small to negligible.

In summary, according to our mean parameters, the initial model (Fig. 1) can be simplified as shown in Fig. 3. The model is now composed of two compartments of very different sizes, exchanging with each other, and supplied almost exclusively with the free plasma cholesterol inflow. Only free adrenal cholesterol returns to plasma. Furthermore, if free adrenal cholesterol is the precursor of the adrenal steroid hormones, since the inflow of free plasma cholesterol is of the order of $50 \mathrm{mg} /$ day and corresponds approximately to the needs for steroid hormone production $(25,26)$, a major part of free adrenal cholesterol must return to plasma as steroid hormones rather than in unmodified form.

In view of the scattering of the experimental data, the standard deviations of the calculated parameters are elevated, particularly in the zona "reticularis" (Table I). However, in practically each patient and at each time interval, the specific activities of free and esterified adrenal cholesterol are slightly to definitely higher in the zona reticularis than in the zona fasciculata (2). This systematic difference in the specific activities of adrenal cholesterol suggests that the two zones equilibrate differently with plasma cholesterol. According to our results (Table I) the two zones differ mainly by the turnover rate of free adrenal cholesterol (ki1) which appears to be almost twice as important in the zona "fasciculata" as in the zona "reticularis." Everything being equal, this faster turnover of free adrenal cholesterol in the zona "fasciculata" corresponds to a higher inflow of free plasma cholesterol (p10) and still more to a greater hydrolysis of esterified adrenal cholesterol $\left(\mathrm{p}_{12}\right)$. In addition, the synthesis of adrenal cholesterol appears to be more important in the zona "reticularis"; however, this synthesis seems to be relatively small since, even in the zona reticularis, it hardly reaches $11 \%$ of the free plasma cholesterol inflow ( $p^{\prime}{ }_{10}$ $\approx 0.28$ ) whereas in the zona fasciculata it is practically absent $\left(\mathrm{p}_{10}^{\prime} \approx 0.01\right)$.

The problem of fitting of the computed curves to the

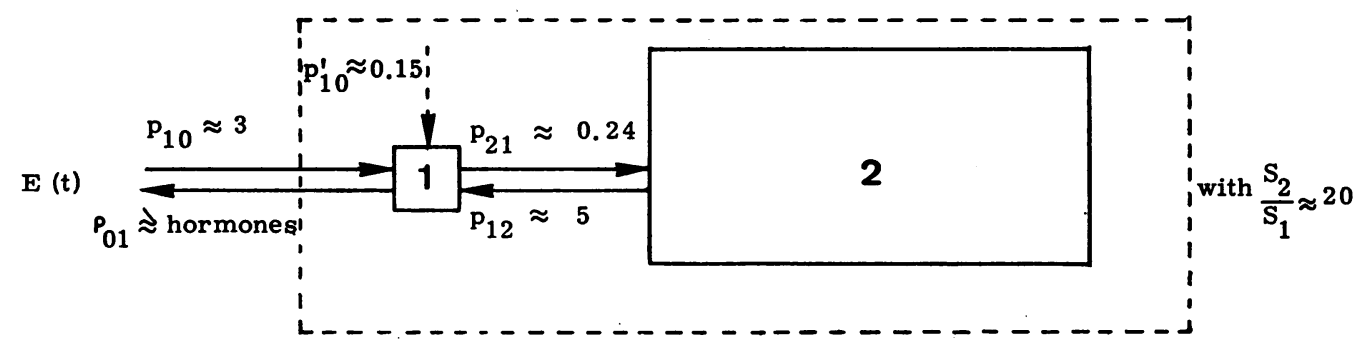

Figure 3 Modified model of adrenal cholesterol metabolism. 
TABLE II

Specific Activities of the Various Adrenal Cholesteryl Esters Under Conditions of ACTH Suppression

\begin{tabular}{|c|c|c|c|c|c|c|c|}
\hline & \multicolumn{6}{|c|}{ Patient } & \multirow{2}{*}{$\begin{array}{l}\text { Concen- } \\
\text { trationst }\end{array}$} \\
\hline & Wei & Duf & V. Eck. & Hol & Bosq & V. Ac* & \\
\hline & \multicolumn{6}{|c|}{$d p m / m g$ cholesterol } & $\%$ \\
\hline$\Delta \mathbf{s}$ & 151 & 216 & 257 & 258 & 177 & 423 & $11 \pm 5.1$ \\
\hline$\Delta \mathbf{z}$ & 115 & 191 & 139 & 177 & 189 & 436 & $12 \pm 4.5$ \\
\hline$\Delta_{2}$ & 127 & 215 & 166 & 189 & 200 & 454 & $11 \pm 3.8$ \\
\hline$\Delta_{1}$ & 115 & 197 & 148 & 178 & 177 & 451 & $45 \pm 12.6$ \\
\hline$\Delta_{0}$ & 104 & 192 & 146 & 186 & 184 & 406 & $21 \pm 9.1$ \\
\hline Time§ & 1.0 & 1.0 & 2.0 & 2.0 & 4.5 & 12.5 & \\
\hline
\end{tabular}

* $60 \mathrm{mg}$ prednisolone per day.

¥ Values $\pm \mathrm{SD}$, as per cent of total ester cholesterol.

$\$$ Days after the tracer administration.

experimental data and that of their sensitivity to the various parameters will be developed respectively in the discussion and in Appendix II.

Studies under conditions of ACTH suppression. The concentration of free adrenal cholesterol in the cortex of nine suppressed adrenal glands averaged $0.48 \mathrm{mg} /$ $100 \mathrm{mg}$ (range: $0.29-0.63$ ). The corresponding mean concentration of esterified adrenal cholesterol was 6.3 $\mathrm{mg} / 100 \mathrm{mg}$ (range: 4.2-9.1) and the mean ratio of esterified to free adrenal cholesterol concentrations was 15.0 (range: 7.6-23.7). All these values are not significantly different from those obtained under control conditions (2).
It has previously been shown that the rapid equilibration of adrenal cholesterol between the subcellular organelles, the cytosol, and the liposomes is not modified by dexamethasone suppression (2). Table II indicates that the same holds true after cholesterol- $4-{ }^{14} \mathrm{C}$ administration for the equilibration of labeled cholesterol between the various adrenal cholesteryl esters: indeed, under dexamethasone, the specific activities of the latter are similar to each other as found under normal conditions. Besides, whereas the specific activities of the various adrenal cholesteryl esters, however similar to each other, normally tend to increase very slightly but significantly with the unsaturation of the fatty acid moiety (2), these slight differences are further reduced under dexamethasone suppression and only the specific activities of the $\Delta_{4}$-cholesteryl esters during the first 2 days seem still to be significantly more elevated.

Finally, as shown by Table III, the evolution in time of free and esterified adrenal cholesterol specific activities in comparison to the specific activities of free, esterified, and total plasma cholesterol, is quite comparable to that observed in the control studies (2), although the zonal differences seem to be somewhat attenuated. In this respect it is also remarkable that in the adrenal gland operated 12.5 days after the tracer infusion the specific activity of free adrenal cholesterol is higher than that of free plasma cholesterol, the specific activity of esterified adrenal cholesterol is higher than that of free adrenal cholesterol, and the specific

TABLE III

Comparison to Each Other of Specific Activities of Plasma and Adrenal Cholesterol Under Conditions of ACTH Suppression

\begin{tabular}{llccccc}
\hline & & \multicolumn{5}{c}{ Time (days) } \\
\cline { 3 - 7 } & & $0-6(\mathrm{~N}=14)$ & $1(\mathrm{~N}=4)$ & $2(\mathrm{~N}=4)$ & 4-6 (N=6) & $\vdots 2.5(\mathrm{~N}=1)$ \\
\hline $\mathrm{Fr} / \mathrm{Fp}$ & Range & & $0.32-0.52$ & $0.61-0.67$ & $0.51-1.03$ & 1.22 \\
& Mean & 0.64 & 0.45 & 0.63 & 0.77 & \\
$\mathrm{Fr} / \mathrm{Tp}$ & Range & & $0.42-0.82$ & $0.58-0.79$ & $0.48-0.93$ & 1.06 \\
& Mean & 0.69 & 0.71 & 0.67 & 0.70 & \\
$\mathrm{Fr} / \mathrm{Ep}$ & Range & & $0.47-1.20$ & $0.62-0.86$ & $0.47-1.09$ & 0.99 \\
& Mean & 0.81 & 0.96 & 0.71 & 0.78 & \\
$\mathrm{Ff} / \mathrm{Tp}$ & Range & & $0.38-0.87$ & $0.55-0.75$ & $0.36-0.74$ & 1.11 \\
& Mean & 0.63 & 0.69 & 0.62 & 0.60 & \\
$\mathrm{Er} / \mathrm{Fr}$ & Range & & $0.15-0.54$ & $0.23-0.40$ & $0.44-0.93$ & 1.03 \\
& Mean & 0.44 & 0.25 & 0.31 & 0.65 & \\
$\mathrm{Ef} / \mathrm{Ff}$ & Range & & $0.12-0.42$ & $0.26-0.32$ & $0.44-0.75$ & 1.09 \\
& Mean & 0.40 & 0.19 & 0.29 & 0.61 & \\
\hline
\end{tabular}

$\mathrm{F}$, specific activities (SA) of free cholesterol: Fr in reticularis, $\mathrm{Ff}$ in fasciculata, $\mathrm{Fp}$ in plasma; $\mathrm{E}, \mathrm{SA}$ of cholesteryl esters: $\mathrm{Er}$ in reticularis, Ef in fasciculata, Ep in plasma; $\mathrm{Tp}, \mathrm{SA}$ of total plasma cholesterol; $\mathrm{N}$, number of observations. 


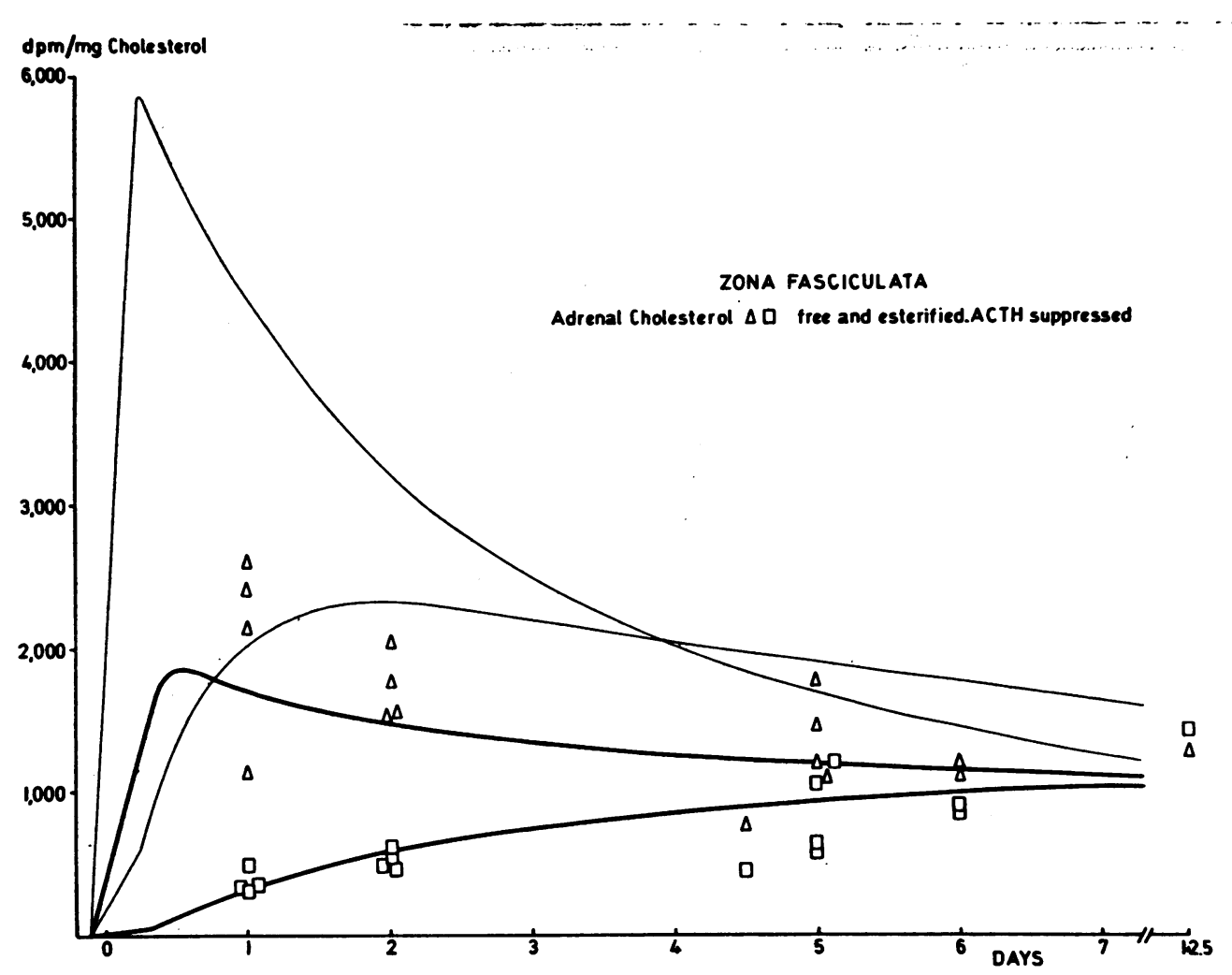

Figure 4 Influence of ACTH suppression on the equilibration of plasma and adrenal cholesterol. The thin- and thick-lined curves are those which were computed in the control studies, respectively, for free and esterified plasma and adrenal cholesterol. The symbols represent the individual experimental points of adrenal cholesterol under conditions of ACTH suppression.

activities of free and esterified adrenal cholesterol are both higher in the zona fasciculata than in the zona reticularis. Each of these observations is exactly the opposite of what is found at shorter time intervals after the tracer administration, whether normally or under dexamethasone: it is a reflection of the kinetic precursor-product relationship (27) which exists between the specific activities of free plasma, free adrenal and esterified adrenal cholesterol in each adrenal zone. Fig. 4 illustrates in the zona "fasciculata" the equilibration of plasma and adrenal cholesterol under conditions of ACTH suppression. A very similar picture could be shown for the zona "reticularis."

Studies in Cushing's disease. In one patient with Cushing's disease the tracer was administered $24 \mathrm{hr}$ before adrenalectomy. The specific activities of free and esterified adrenal cholesterol were compared with each other and with those of corresponding plasma cholesterol. As shown in Table IV, adrenal cholesterol was found to equilibrate with plasma cholesterol exactly as in control studies (2); similarly the concentrations of adrenal cholesterol and the proportions of the various adrenal cholesteryl esters were not different from nor- mal (2), the concentrations of free and esterified adrenal cholesterol being, respectively, 0.35 and $6.15 \mathrm{mg} / 100$ $\mathrm{mg}$ adrenal gland. On the other hand, the total amount of free cholesterol in the cortex of the two adrenal glands was much increased : $50.4 \mathrm{mg}$.

In one other patient the specific activities of hydrocortisone metabolites were followed during 7 days after cholesterol-4- ${ }^{14} \mathrm{C}$ administration in order to investigate the pool of adrenal cholesterol which serves as a precursor for the synthesis of the adrenal steroid hormones. As shown in Fig. 5, after correction for molecular weight differences the specific activities of hydrocortisone corresponded well to those of free adrenal cholesterol as obtained in the previous control studies. The excretion of the hydrocortisone metabolites (25) during the study was measured daily and averaged 20.7 mg (range: 19.5-22.1).

\section{DISCUSSION}

Previous in vivo work has shown that plasma cholesterol equilibrates homogeneously with free and esterified adrenal cholesterol but enters more rapidly the free adrenal compartment (2). In vitro experiments indi- 


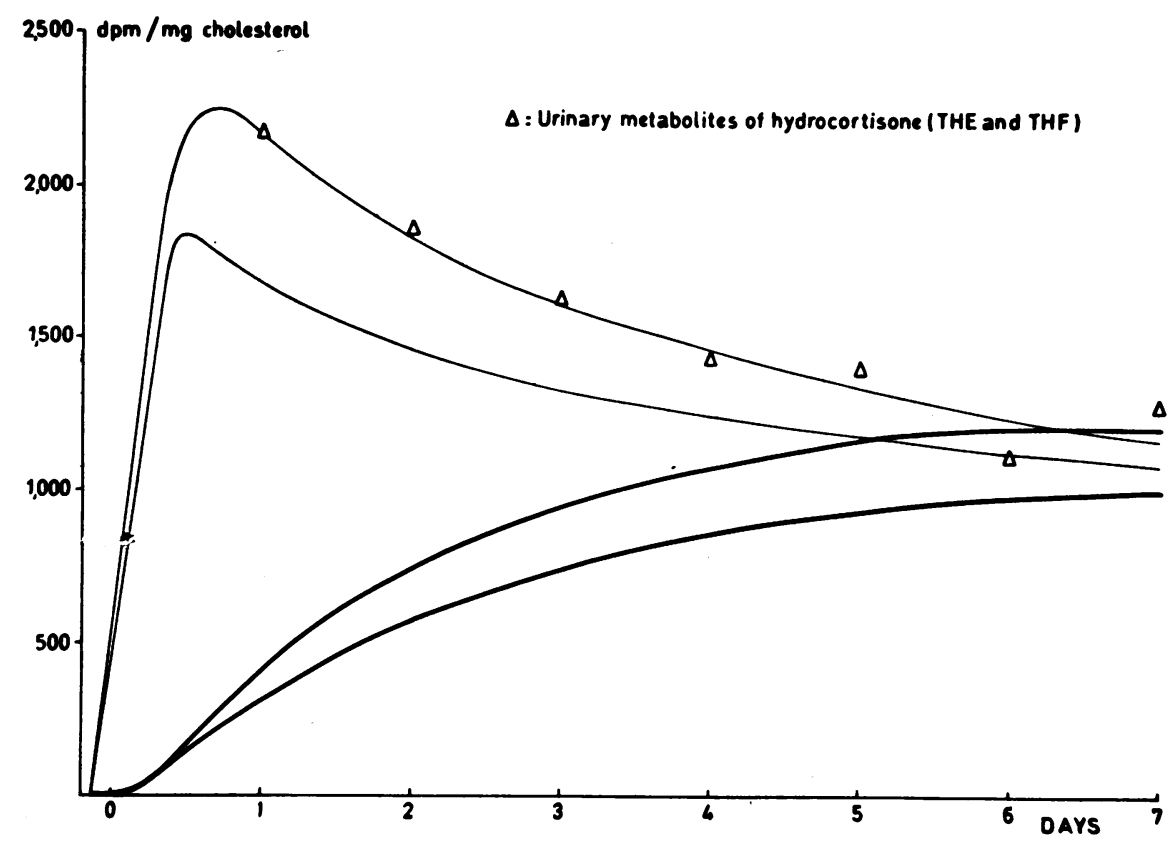

FIGURE 5 Equilibration of plasma cholesterol with adrenal cholesterol serving as precursor to hydrocortisone: study of a patient with Cushing's disease. The thin-lined curves are those which were previously computed for free adrenal cholesterol in the zona reticularis (above) and in the zona fasciculata (below). The thick-lined curves correspond similarly to esterified adrenal cholesterol in the two cortical zones. The symbols represent the specific activities of the patient's hydrocortisone metabolites expressed in dpm per milligram of cholesterol.

cate that the same holds true, to a large extent, for adrenal cholesterol synthesized in situ (10). Our model composed of two homogeneous intracellular compartments of adrenal cholesterol, one free, the other one esterified, exchanging with each other through esterification and hydrolysis $(28,29)$, and renewed by an inflow from plasma or by a local synthesis of free cholesterol, appears therefore to be justified from a kinetic point of view. However, both in vivo and in vitro studies indicate that this model should be explored separately in the zona reticularis and in the zona fasciculata since the two zones of the adrenal cortex equilibrate differently with plasma cholesterol and synthesize different amounts of adrenal cholesterol.

In our kinetic study which extends over several days, free and esterified plasma cholesterol can similarly be viewed as two homogeneous compartments. Indeed, free plasma cholesterol equilibrates rapidly between the various plasma lipoproteins (30). As for the many plasma cholesteryl esters, after cholesterol-4- ${ }^{14} \mathrm{C}$ administration, their specific activities are identical to each other within each lipoprotein at any time, they become equal in the different lipoproteins within 2-3 days, and although differing according to the plasma lipoprotein during the first days, they are nevertheless similar for the different esters when compared with the corresponding specific activities of free plasma cholesterol (30).

The mechanism of exchange between plasma and intracellular cholesterol is not well understood. Free

\section{TABLE IV}

Equilibration of Plasma and Adrenal Cholesterol in a Case of Cushing's Disease (Time: 24 hr after Tracer Administration)

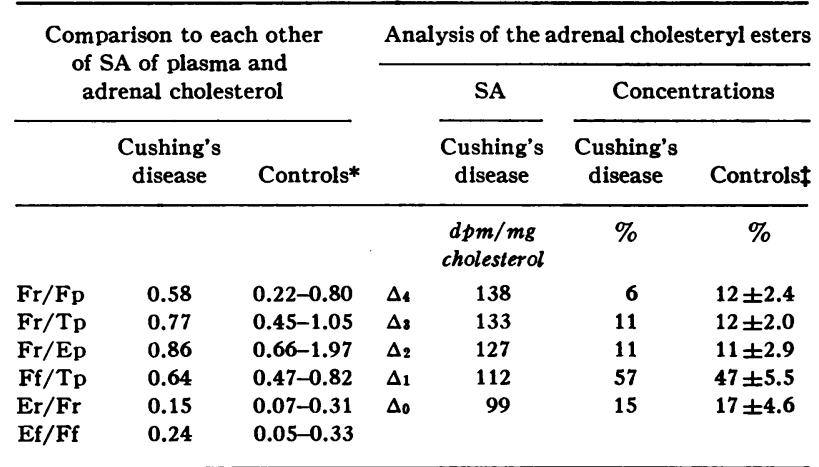

F, SA of free cholesterol : Fr in reticularis, Ff in fasciculata, Fp in plasma; E, SA of cholesteryl esters: $\mathrm{Er}$ in reticularis, Ef in fasciculata, Ep in plasma; Tp, SA of total plasma cholesterol; $\Delta_{n}$, number of double bindings in fatty acid moiety of cholesteryl esters.

* Reference (2). Ranges in 12 controls; Time, 0.5-2 days after tracer administration.

$\ddagger$ Reference (2). Means $\pm \mathrm{SD}$; ranges in 11 controls. 
plasma and free intracellular cholesterol are known to equilibrate progressively with each other (31) and this equilibration might be controlled in some fashion by plasma lecithin-cholesteryl transferase (32). As for esterified plasma cholesterol, it is thought to be hydrolyzed by the liver and by the reticulo-endothelial system (33) although one cannot exclude that other tissues could take up and hydrolyse the plasma cholesteryl esters (34). We therefore consider the possibility of both free and esterified plasma cholesterol uptake, but we postulate, as proposed by some authors, that the plasma cholesteryl esters accumulate directly and selectively into the large adrenal esterified pool before hydrolysis (9, $35)$.

The analysis of our data pertaining to this equilibration of free and esterified adrenal cholesterol with free and esterified plasma cholesterol provides some reasonable parameters. With regard to free adrenal cholesterol, our results indicate that it can be viewed as a very dynamic compartment, turning over 5-10 times per day. This is not too unexpected if one considers that free adrenal cholesterol is a small metabolic pool which serves as precursor for the synthesis of the adrenal steroid hormones $(36,37)$. However, most of free adrenal cholesterol also takes part in the structure of the intracellular membranes (4) which are exceptionally abundant in the adrenal cortex (38). This very abundance of the intracellular membranes might be, as proposed by Fawcett, Long, and Jones (38), a means of storing and making rapidly available sufficient amounts of free adrenal cholesterol, i.e., the immediate precursor of the steroid hormones; it might also facilitate the equilibration of free plasma cholesterol with free adrenal cholesterol and therefore the inflow of free plasma cholesterol into the adrenal cells. The role of free adrenal cholesterol in the structure of the membranes makes it imperative for reasons of structural stability that its concentration be constant. It is indeed remarkable how free adrenal cholesterol varies little despite important variations of the adrenal functional state (2).

Which then are the possible mechanisms of control for free cholesterol concentration in the normal adrenal glands?

(a) Free adrenal cholesterol synthesis: according to our present data and supported by in vitro experiments (10), this synthesis seems to be low under normal circumstances, particularly in the zona fasciculata.

(b) Free plasma cholesterol inflow: if the local synthesis is low and since the plasma cholesteryl esters do not enter the adrenal cell within the frame of our model, the free plasma cholesterol inflow appears to be the most important source of adrenal cholesterol. However, as will be discussed below, this inflow proceeds to some extent in continuous and autonomous fashion and may not be a perfect mechanism of adjustment to brisk variations in ACTH stimulation.

(c) Esterified adrenal cholesterol hydrolysis: it is this hydrolysis which seems to contribute most efficiently to free adrenal cholesterol turnover and might therefore play a major role in the normal control of free adrenal cholesterol concentration. Indeed, according to our parameters, free and esterified adrenal cholesterol exchange with each other very actively; esterified adrenal cholesterol is not, as sometimes felt, a quiescent reservoir $(5,39)$. Despite its large size, this compartment is constantly turned over, a fourth to a fifth of its content being renewed every day. On the other hand it has also been known for a long time, that the adrenal cholesteryl esters are exquisitely sensitive to an acute ACTH stimulation which induces their rapid hydrolysis and depletion (40); since this hydrolysis and this depletion are not prevented, the mobilization of the adrenal cholesteryl esters can be faster than any sufficient adjustment which might possibly take place through increased adrenal cholesterol synthesis or increased plasma cholesterol uptake. Consequently, esterified adrenal cholesterol might be viewed not only as a buffer which at any particular time controls the content of the free adrenal compartment but additionally as a rapid source of supply under conditions of acute stress (in this regard see also Appendix II).

The chemical distribution of the adrenal cholesteryl esters is very different from that found in plasma (3). This characteristic distribution could result from a selective and direct accumulation of plasma cholesteryl esters or from a local esterification of free adrenal cholesterol $(9,35,41)$. Our kinetic study favors the second hypothesis and is again supported by in vitro experiments (10). On the other hand it is thought that except for cholesterol sulfate, all adrenal cholesteryl esters must be hydrolyzed before conversion into steroid hormones $(36,37,42)$. Our observations suggesting that the adrenal cholesteryl esters do not leave the adrenal cell directly but are first hydrolyzed are in agreement with this opinion.

In this regard it is remarkable how the turnover rates resulting from the intracellular esterification and hydrolysis are inversely proportional to the size of the esterified and the free adrenal compartments, respectively. Considering that we did not impose these sizes, the finding of such a precise relationship between the parameters calculated and the actual amounts of free and esterified adrenal cholesterol is evidence for the validity of the model.

Cholesterol sulfate deserves a special comment although its specific activity could not be measured in the present study because of its very low concentration. Indeed, the concentration of adrenal cholesterol sulfate is several hundred times lower than that of free adrenal 
cholesterol (43): in opposition to the fatty acid esters it does not accumulate in the adrenal cell. It might therefore be viewed as a simple intermediary step in the conversion of free adrenal cholesterol into steroid hormone sulfates and perhaps also as part of another mechanism of regulation of free adrenal cholesterol concentration.

The zona fasciculata and the zona reticularis are thought to form a functional unit (1). However the concentration of adrenal cholesterol, particularly esterified, tends to be higher in the zona fasciculata $(1,10)$. Corresponding to this higher concentration, the local synthesis of adrenal cholesterol, everything being equal, is lower, presumably because the feedback inhibition is more important than in the zona reticularis (10). The results obtained in our present in vivo studies are compatible with the zonal difference of cholesterol synthesis found in the in vitro experiments. Furthermore, according to the present studies, free adrenal cholesterol turns over more rapidly in the zona fasciculata: it is more rapidly renewed by the inflow of free plasma cholesterol and by the hydrolysis of the more abundant esterified adrenal cholesterol. Despite its larger "reserves" of cholesterol the zona fasciculata does not therefore seem to be a resting functional complement to the zona reticularis. Its apparently faster cholesterol metabolism might correspond to a faster conversion into steroid hormones as shown by our in vitro experiments, at least as far as glucocorticosteroid hormones are concerned (10).

To close the discussion of the parameters obtained in the present investigation one should stress that our biological model is just a step in the study of adrenal cholesterol physiology. It no doubt constitutes an oversimplification. This might explain the absence of perfect correspondence between the computed curves of the adrenal cholesteryl esters and the corresponding experimental points which might be due for instance to a cellular heterogeneity within each adrenal zone; a functional heterogeneity of the various liposomes within each adrenal cell and even of the cholesteryl esters within each liposome cannot be excluded either. Finally, one should keep in mind the possibility of an uptake of some esterified plasma cholesterol into the free adrenal compartment followed by hydrolysis and reesterification.

What is the regulatory role of ACTH on adrenal cholesterol metabolism? Our data indicate that the equilibration of plasma with adrenal cholesterol can proceed unmodified, at least for a certain time, in the absence of ACTH. In other words, the conversion of adrenal cholesterol into steroid hormones is not necessary for the renewal of adrenal cholesterol from plasma cholesterol and for the constant intracellular exchanges taking place between the free and esterified compartments: the production of steroid hormones constitutes a superim- posed phenomenon which is grafted upon a continuous and autonomous mechanism of plasma and adrenal cholesterol equilibration. In the absence of $\mathrm{ACTH}$ free adrenal cholesterol presumably returns to plasma in an unmetabolized form whereas under the influence of ACTH a major fraction (see below) is first diverted towards the pathways of steroid hormone synthesis. This concept is compatible with the known mode of action of ACTH which accelerates the conversion of adrenal cholesterol into $\Delta_{5}$-pregnenolone and of $\Delta_{5}$-pregnenolone into steroid hormones $(11,44)$. It also confirms and explains the experimental observations by Sayers, Sayers, Frey, White, and Long (40) who showed that hypophysectomized rats are still capable of replenishing depleted stores of adrenal cholesterol. Finally, it suggests that except for the optional conversion into steroid hormones, the physiology of cholesterol in the adrenal cortex might be similar to that of cholesterol in other tissues $(12,13)$.

If the equilibration of plasma and adrenal cholesterol can proceed independently from $\mathrm{ACTH}$, there is no doubt, however, that ACTH can modify this equilibration. Indeed, as already mentioned, ACTH produces a rapid and striking depletion of the adrenal cholesteryl esters (40), presumably accompanied by hydrolysis (45). This depletion is secondary to the accelerated conversion of adrenal cholesterol into steroid hormones since it is abolished when the hormone synthesis is inhibited by cycloheximide or aminogluthetimide $(46,47)$. $\mathrm{ACTH}$ must also somehow increase the inflow of plasma cholesterol into the adrenal cortex since under conditions of more prolonged stimulation the equilibration of plasma and adrenal cholesterol is accelerated (personal observations) ; furthermore, despite a complete depletion of the esterified reserves and despite what seems to be a moderate level of cholesterol synthesis (10), the concentration of free adrenal cholesterol remains stable and the production of the steroid hormones does not fall. On the other hand, in Cushing's disease, i.e., a situation of chronic hyperstimulation, the adrenal glands are not depleted, and the studies by Dexter, Fishman, Ney, and Liddle (47) indicate that ACTH is even capable of very much increasing adrenal cholesterol concentration when cholesterol side-chain cleavage has been inhibited by aminogluthetimide. Thus, although ACTH is not directly indispensable for adrenal cholesterol turnover, it indirectly controls the importance of the latter and somehow adjusts it to the needs in steroid hormone precursors. One can only speculate about the mechanisms of this adjustment: ACTH might accelerate the passive exchanges between plasma and adrenal cholesterol as a result of a steeper gradient of concentration between plasma and the adrenal cell, of an increased vascularization and thus increased perfusion pressure, and of a nonspecific 
trophic effect with proliferation of the cellular membranes (38). In any case, this adjustment might explain why, according to our data, the inflow of free plasma cholesterol is of the order of $50 \mathrm{mg} /$ day and approximately corresponds to the needs of the daily steroid hormone production. Similarly, one could attribute the gradient of cholesterol concentration and metabolic activity throughout the adrenal cortex to a sequential perfusion (48) and stimulation by ACTH; the work by Urquhart (49) is of interest in this respect since it demonstrates the close relationship which exists between perfusion pressure and ACTH stimulation. Finally our observations in Cushing's disease are not too unexpected: they do not reveal any qualitative difference from normal, whereas from a quantitative point of view, since the adrenal glands are hyperplastic, the total amount of adrenal cholesterol is much increased, and the parameters of adrenal cholesterol metabolism need not be considerably accelerated to account for an increased production of adrenal steroid hormones.

\section{APPENDIX I. ORDER OF THE MODEL}

One could argue that our model does not account for the delays which take place between the uptake of plasma cholesterol, its incorporation into the various adrenal compartments and its conversion into hydrocortisone. However, considering that our study extends over 7 days these delays appear to be relatively negligible. This is supported by the analysis (50) of the experimental data obtained in the patient with Cushing's disease on the conversion of free plasma cholesterol into plasma hydrocortisone or more precisely into the urinary metabolites of hydrocortisone (Fig. 6). Indeed, if $\chi_{1}(t)$ is the SA of the precursor, $\chi_{2}(t)$ the SA of the product, and $r$, a dummy variable, it can be seen on Fig. 6 that:

$$
\lim _{t \rightarrow 0} \frac{\chi_{2}(t)}{\chi_{1}(t)} \cdot \frac{1}{t^{r}} \neq 0 \text { and } \neq \infty \text { when } r=1 .
$$

This indicates that the conversion of plasma cholesterol into hydrocortisone can be described by a first order model.

\section{APPENDIX II. CALCULATION OF THE PARAMETERS}

\section{Input curves}

The input curves of free and esterified plasma cholesterol specific activities were fitted to all experimental data of the 24 patients by a least squares method. Their respective mathematical expressions are as follows:

$$
\begin{aligned}
\text { when } & t \leq t_{0}\left\{\begin{array}{l}
E_{1}(t)=a t \\
E_{2}(t)=b t
\end{array}\right. \\
\text { when } & t \geq t_{0}\left\{\begin{array}{l}
E_{1}(t)=\underset{j}{\Sigma} A_{j e} e^{-\lambda j t} \quad j=1,2 \\
E_{2}(t)=\underset{j}{\Sigma} B_{j e}{ }^{-\beta j t} \quad j=1,2
\end{array}\right.
\end{aligned}
$$

and

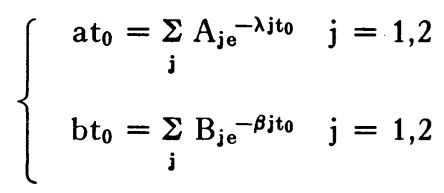

The numerical solutions are:

$$
E_{1}(t)=2913 \times e^{-0.132 t}+2969 \times e^{-0.665 t}
$$
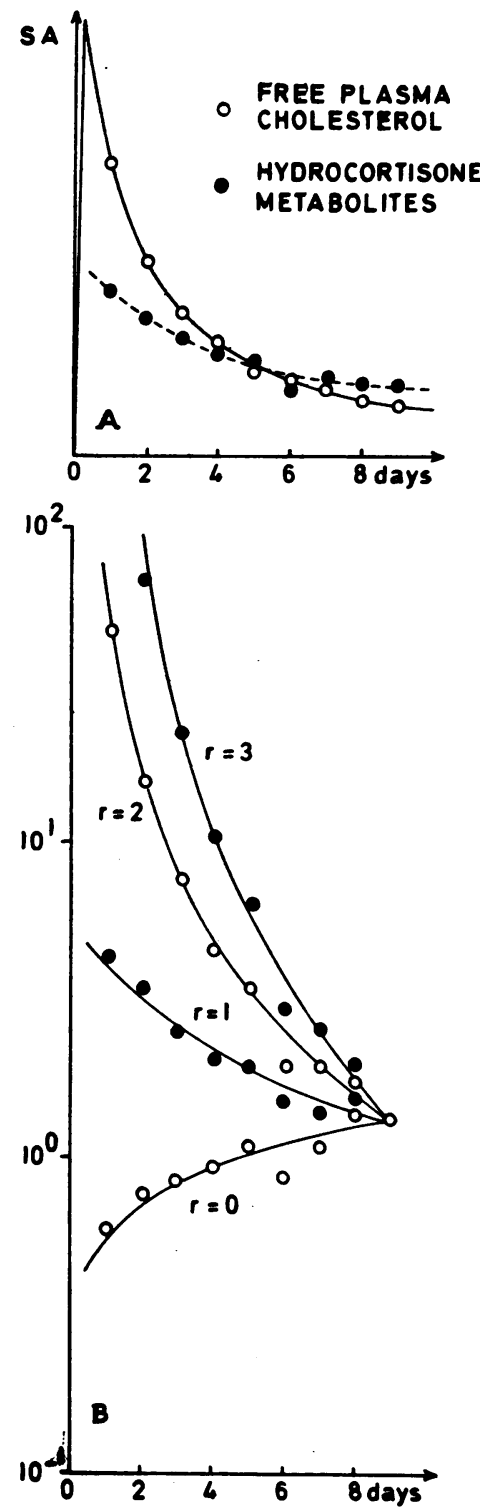

FIGURE 6 Study of the order of the model. Curves A: specific activities (SA) of free plasma cholesterol and of hydrocortisone metabolites. Curves B: $\lim _{t \rightarrow 0} \frac{\chi_{2}(t)}{\chi_{1}(t) \cdot t^{r}}$ with $\chi_{1}(t)$ : SA of free plasma cholesterol, $\chi_{2}(t)$ : SA of hydrocortisone metabolites and $r$ : order of the model. 


$$
\begin{aligned}
\text { SD }(\text { weights }=1) & = \pm 441 \quad \pm 0.040 & \pm 321 & \pm 0.147 \\
\mathrm{E}_{2}(\mathrm{t}) & =2759 \times \mathrm{e}^{-0.079 \mathrm{t}} & & -2130 \times \mathrm{e}^{-1.800 \mathrm{t}}
\end{aligned}
$$$$
\mathrm{SD}(\text { weights }=1)= \pm 232 \quad \pm 0.017 \quad \pm 229 \pm 0.300
$$

\section{Adrenal curves}

Analytical solutions. The analytical form of the adrenal cholesterol curves was calculated from the plasma cholesterol curves by a Laplace Transform and its inverse. Let us write:

$\mathrm{p}_{1}=\frac{\rho_{10}}{\mathrm{~S}_{1}}, \mathrm{p}_{2}=\frac{\rho_{12}}{\mathrm{~S}_{1}}, \mathrm{p}_{3}=\frac{\rho_{01}+\rho_{21}}{\mathrm{~S}_{1}}$,

$$
\mathrm{p}_{4}=\frac{\rho_{21}}{\mathrm{~S}_{2}}, \mathrm{p}_{5}=\frac{\rho_{02}+\rho_{12}}{\mathrm{~S}_{2}}
$$

All these parameters have to be positive or null; consequently the eigenvalues $-\alpha_{1}$ and $-\alpha_{2}$ of the matrix //A(p)// are always real and negative.

Using a theorem on partial fractions (51) and the symmetry which exists between $p_{1}$ and $\left(p_{5}-p_{4}\right), p_{2}$ and $p_{4}, p_{3}$ and $p_{5}$ we can easily compute the solutions $\mathrm{X}_{1}(t), \mathrm{X}_{2}(t)$ of our system. When $t \leq t_{0}$ :

$$
\begin{aligned}
& \mathrm{X}_{1}(\mathrm{t})= \frac{\mathrm{ap}_{1} \mathrm{p}_{5}+\mathrm{bp} \mathrm{p}_{2}\left(\mathrm{p}_{5}-\mathrm{p}_{4}\right)}{\alpha_{1} \alpha_{2}} \\
&+\sum_{\mathrm{k}=1}^{2}\left(\mathrm{ap}_{1}-\frac{a \mathrm{p}_{1} \mathrm{p}_{5}+\mathrm{bp}_{2}\left(\mathrm{p}_{5}-\mathrm{p}_{4}\right)}{\alpha_{\mathrm{k}}}\right) \frac{\mathrm{e}^{-\alpha_{\mathbf{k}} \mathrm{t}}}{\delta_{\mathrm{k}}} \\
& \mathrm{X}_{2}(\mathrm{t})=\frac{\mathrm{ap}_{1} \mathrm{p}_{4}+\mathrm{bp}_{3}\left(\mathrm{p}_{5}-\mathrm{p}_{4}\right)}{\alpha_{1} \alpha_{2}} \\
&+\sum_{\mathrm{k}=1}^{2}\left(\mathrm{~b}\left(\mathrm{p}_{5}-\mathrm{p}_{4}\right)-\frac{\mathrm{ap}_{1} \mathrm{p}_{4}+\mathrm{bp}_{3}\left(\mathrm{p}_{5}-\mathrm{p}_{4}\right)}{\alpha_{\mathrm{k}}}\right) \frac{\mathrm{e}^{-\alpha_{\mathbf{k}} \mathrm{t}}}{\delta_{\mathbf{k}}}
\end{aligned}
$$

with

$$
\delta_{\mathrm{k}}=\left\{\begin{array}{l}
\delta_{1}=\alpha_{2}-\alpha_{1} \\
\delta_{2}=-\delta_{1}
\end{array}\right.
$$

When $t \geq t_{0}$ we take into account the initial conditions $X_{1}\left(t_{0}\right)$ and $\mathrm{X}_{2}\left(\mathrm{t}_{0}\right)$ and the multiexponential function generators of the precursors. We obtain:

$$
\begin{aligned}
\mathrm{X}_{1}(\mathrm{t})= & \sum_{\mathrm{k}=1}^{2}\left[\left(\mathrm{p}_{5}-\alpha_{\mathrm{k}}\right)\left(\mathrm{X}_{1}\left(\mathrm{t}_{0}\right)+\mathrm{p}_{1} \sum_{\mathrm{j}=1}^{2} \frac{\mathrm{A}_{\mathrm{j}}}{\lambda_{\mathrm{j}}-\alpha_{\mathrm{k}}}\right)\right. \\
& \left.+\mathrm{p}_{2}\left(\mathrm{X}_{2}\left(\mathrm{t}_{0}\right)+\left(\mathrm{p}_{5}-\mathrm{p}_{4}\right) \sum_{\mathrm{j}=1}^{2} \frac{\mathrm{B}_{\mathrm{j}}}{\beta_{\mathrm{j}}-\alpha_{\mathrm{k}}}\right)\right] \frac{\mathrm{e}^{-\alpha_{\mathrm{k}} \mathrm{t}}}{\delta_{\mathrm{k}}} \\
& +\mathrm{p}_{1} \sum_{\mathrm{j}=1}^{2} \frac{\left(\mathrm{p}_{5}-\lambda_{\mathrm{j}}\right)}{\prod_{\mathrm{k}=1}^{2}\left(\lambda_{\mathrm{j}}-\alpha_{\mathrm{k}}\right)} \mathrm{e}^{-\lambda_{\mathrm{j}} \mathrm{t}} \\
& +\mathrm{p}_{2}\left(\mathrm{p}_{5}-\mathrm{p}_{4}\right) \sum_{\mathrm{j}=1}^{2} \frac{\mathrm{B}_{\mathrm{j}}}{\prod_{\mathrm{k}=1}^{2}\left(\beta_{\mathrm{j}}-\alpha_{\mathrm{k}}\right)} \mathrm{e}^{-\beta_{\mathrm{j}} \mathrm{t}}
\end{aligned}
$$

$$
\begin{aligned}
\mathrm{X}_{2}(\mathrm{t})= & \sum_{\mathrm{k}=1}^{2}\left[\mathrm{p}_{4}\left(\mathrm{X}_{1}\left(\mathrm{t}_{0}\right)+\mathrm{p}_{1} \sum_{\mathrm{j}=1}^{2} \frac{\mathrm{A}_{\mathrm{j}}}{\lambda_{\mathrm{j}}-\alpha_{\mathrm{k}}}\right)\right. \\
& \left.+\left(\mathrm{p}_{3}-\alpha_{\mathrm{k}}\right)\left(\mathrm{X}_{2}\left(\mathrm{t}_{0}\right)+\left(\mathrm{p}_{5}-\mathrm{p}_{4}\right) \sum_{\mathrm{j} /=1}^{2} \frac{\mathrm{B}_{\mathrm{j}}}{\beta_{\mathrm{j}}-\alpha_{\mathrm{k}}}\right)\right] \\
& \times \frac{\mathrm{e}^{-\alpha_{\mathrm{k}} \mathrm{t}}}{\delta_{\mathrm{k}}}+\mathrm{p}_{1} \mathrm{p}_{4} \sum_{\mathrm{j}=1}^{2} \frac{\mathrm{A}_{\mathrm{j}}}{\prod_{\mathrm{k}=1}^{2}\left(\lambda_{\mathrm{j}}-\alpha_{\mathrm{k}}\right)} \mathrm{e}^{-\lambda_{\mathrm{j} t}} \\
& +\left(\mathrm{p}_{5}-\mathrm{p}_{4}\right) \sum_{j=1}^{2} \frac{\left(\mathrm{p}_{3}-\beta_{\mathrm{j}}\right) \mathrm{B}_{\mathrm{j}}}{\prod_{k=1}^{2}\left(\beta_{\mathrm{j}}-\alpha_{\mathrm{k}}\right)}
\end{aligned}
$$

Numerical solutions. The following numerical solutions were obtained. In the zona "fasciculata":

$$
\begin{aligned}
& \mathrm{X}_{1}(\mathrm{t})=- 546 \times \mathrm{e}^{-10.39 t}+2964 \times \mathrm{e}^{-0.075 t} \\
&-1711 \times \mathrm{e}^{-0.132 t}+750 \times \mathrm{e}^{-0.665 t}-0.49 \times \mathrm{e}^{-0.079 t}+0.00087 \times \mathrm{e}^{-1.80 \mathrm{t}} \\
& \mathrm{X}_{2}(\mathrm{t})= 12.5 \times \mathrm{e}^{-10.39 \mathrm{t}}+4376 \times \mathrm{e}^{-0.075 \mathrm{t}} \\
&-3933 \times \mathrm{e}^{-0.132 t}-405 \times \mathrm{e}^{-0.665 t} \\
&-0.72 \times \mathrm{e}^{-0.079 t}+0.0011 \times \mathrm{e}^{-1.83 \mathrm{t}}
\end{aligned}
$$

In the zona "reticularis":

$$
\begin{aligned}
\mathrm{X}_{1}(\mathrm{t})=- & 1180 \times \mathrm{e}^{-5.69 t}+11845 \times \mathrm{e}^{-0.117 t} \\
& -10289 \times \mathrm{e}^{-0.132 \mathrm{t}}+10632 \times \mathrm{e}^{-0.665 t} \\
& +29.5 \times \mathrm{e}^{-0.079 \mathrm{t}}+0.76 \times \mathrm{e}^{-1.80 \mathrm{t}} \\
\mathrm{X}_{2}(\mathrm{t})= & 54.1 \times \mathrm{e}^{-5.69 \mathrm{t}}+22201 \times \mathrm{e}^{-0.117 t} \\
& -21620 \times \mathrm{e}^{-0.132 \mathrm{t}}-641 \times \mathrm{e}^{-0.665 t} \\
& +55.6 \times \mathrm{e}^{-0.078 \mathrm{t}}+0.98 \times \mathrm{e}^{-1.83 \mathrm{t}}
\end{aligned}
$$

Fitting. Although the maximum likelihood method gives the most efficient estimators of the parameters, since the frequency functions of the deviations in each curve at each moment were unknown, the relative deviations were assumed to be homoscedastic. The initial values of the parameters were estimated with an analog computer and the adrenal curves were fitted thereafter to the experimental data with the help of a computer by the method of the gradient combined with a Monte Carlo sounding in order to minimize the sums of the squares of the relative deviations; when made to vary by more than $100 \%$ the initial estimates always converged on the same answers. The two adrenal curves were found to be equally determinant to the final parameters, the sums of the squares of the relative deviations being, respectively, 0.746 and 1.22 for free and esterified cholesterol in the zona fasciculata, 0.818 and 1.21 for free and esterified cholesterol in the zona reticularis. Identical parameters were found through the SAAM 23 program. The SAAM 23 program provided in addition the standard deviations of the parameters and the calculation of the latter was based on the assumption that the fractional standard deviation of each data was 0.2 . 


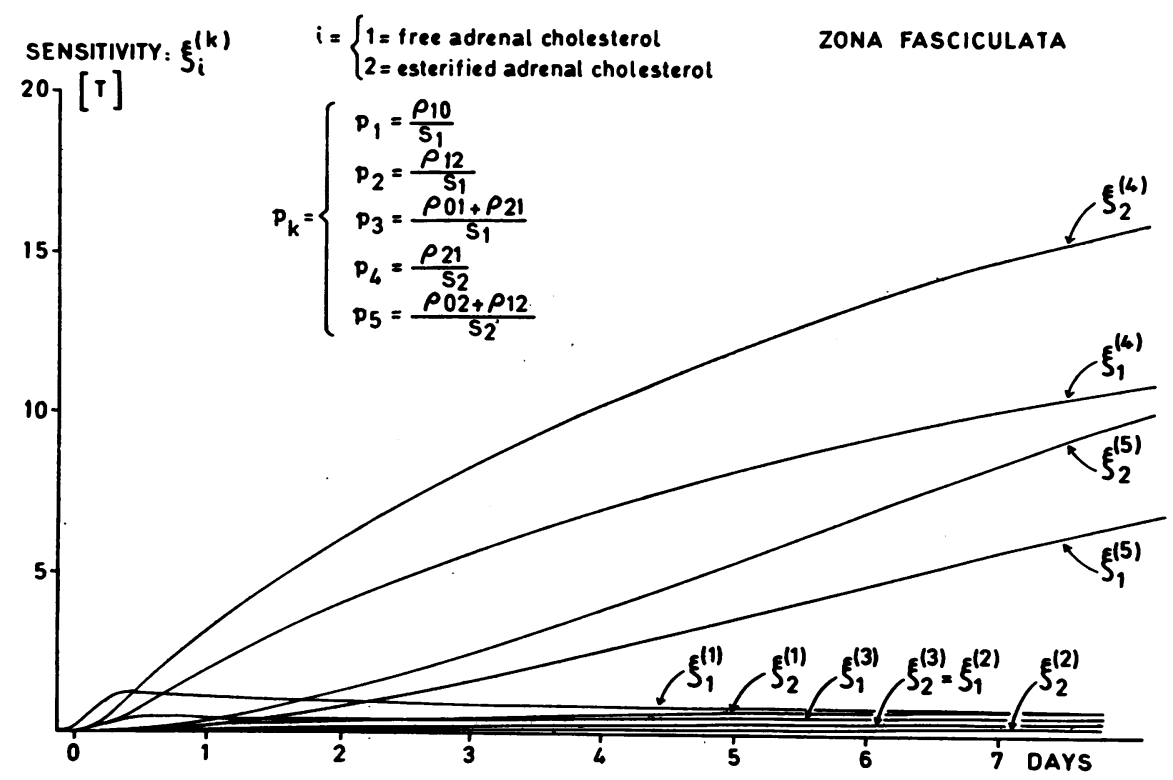

FIGURE 7 Study of the sensitivity of the model to the various parameters. $\xi_{i}(\mathbf{k})=$ sensitivity of state $i$ to parameter $p_{\mathbf{k}}$. The ordinate is expressed in specific activities multiplied by time on an arbitrary scale.

\section{APPENDIX III. \\ PARAMETRIC SENSITIVITY}

With the help of an analog computer we utilized the cosystem technic, as described by King $(20,52)$ and Tomovic (53), in order to explore the sensitivity of the computed curves to the various parameters. $\xi_{1}(\mathbf{k})$ which is the sensitivity of state $i$ (state 1 or free adrenal cholesterol and state 2 or esterified adrenal cholesterol) to the various parameters $p_{k}$ can be written :

$$
\xi_{i}(k)=\frac{\partial \chi}{\partial p_{k}}=\left(\frac{\partial x_{1}}{\partial p_{k}}, \frac{\partial x_{2}}{\partial p_{k}}\right)^{T} .
$$

It is obtained from the following equation:

$$
\begin{aligned}
\left|\frac{\partial \xi^{(k)}}{\partial^{t}}\right|=\|A(p)\| \cdot\left|\xi^{(k)}\right|+\left\|\frac{\partial A_{(p)}}{\partial p_{k}}\right\|^{T} \cdot|\chi(t)| \\
+\left\|\frac{\partial B_{(p)}}{\partial p_{k}}\right\|^{T} \cdot|E(t)|
\end{aligned}
$$

where //A (p)// is the matrix which characterizes the exchanges between the states of the adrenal subsystem and their evential outputs, $/ E(t) /$ the input vector and $/ \chi(t) /$ the state vector.

Fig. 7 gives the sensitivity curves for the zona "fasciculata"; similar curves have been obtained for the zona "reticularis". It can be seen that the computed curves of free and esterified adrenal cholesterol are mostly sensitive to $p_{4}=\rho_{21} / S_{2}$ and to $\mathrm{p}_{5}=\left(\rho_{02}+\rho_{12}\right) / \mathrm{S}_{2}$. In other words, a small variation of these parameters around their numerical value will induce a larger modification of the two computed curves than the same variation of any other of the calculated biological parameters. Such a finding is compatible with the view that the pool of esterified adrenal cholesterol regulates whole adrenal cholesterol metabolism. However it should be added that the logarithmic sensitivities, $\xi_{\mathbf{i}}(\mathbf{k}) \cdot \mathrm{p}_{\mathbf{k}}$, are similar for the five parameters, similar relative deviations of any one of the latter producing similar modifications of all state variables.

\section{ACKNOWLEDGMENTS}

We are grateful to Prof. W. Smets and Dr. W. Mattheiem for their collaboration in this work. The aid of $\mathrm{Mr}$. G. Vamecq in the statistical analysis of our data is also gratefully acknowledged. We are indebted to Mrs. Viviane Keymolen and Vera Verhas for expert technical assistance. This work was supported by contract Euratom-ULBPisa-BIAC-026-63-4 and the Fondation Cancérologique de la Caisse Générale d'Epargne et de Retraite.

\section{REFERENCES}

1. Griffith, K., J. K. Grant, and T. Symington. 1963. A biochemical investigation of the functional zonation of the adrenal cortex in man. J. Clin. Endocrinol. Metab. $23: 776$.

2. Borkowski, A. J., S. Levin, C. Delcroix, and J. Klastersky. 1970. The equilibration of plasma and adrenal cholesterol in man. J. Appl. Physiol. 28: 42.

3. Dailey, R. C., L. Swell, H. Field, Jr., and C. R. Treadwell. 1960. Adrenal cholesterol ester fatty acid composition of different species. Proc. Soc. Exp. Biol. Med. $105: 4$.

4. Korn, E. D. 1966. The structure of biological membranes. The unit membrane theory is reevaluated in light of the data now available. Science (Washington). 153: 1491

5. Heard, R. D. H., E. G. Bligh, M. C. Cann, P. H. Jellinck, V. J. O. Donnel, B. G. Rao, and J. L. Webb. 1956. Biogenesis of sterols and steroid hormones. $R e$ cent Progr. Hormone Res. 12 : 45. 
6. Goodman, DeW. S. 1965. Cholesterol ester metabolism. Physiol. Rev. 45 : 747.

7. Srere, P. A., I. L. Chaikoff, and W. G. Dauben. 1948. The in vitro synthesis of cholesterol from acetate by surviving adrenal cortical tissue. J. Biol. Chem. 176: 829.

8. Werbin, H., and G. V. Le Roy. 1954. Cholesterol-a precursor of tetrahydrocortisone in man. J. Amer. Chem. Soc. 76: 5620 .

9. Longcope, C., and R. H. Williams. 1963. Esterification of cholesterol by homogenates of rat adrenal tissue. Endocrinology. 72: 735.

10. Borkowski, A., C. Delcroix, and S. Levin. Metabolism of adrenal cholesterol in man. II. In vitro studies including a comparison of adrenal cholesterol synthesis with the synthesis of the glucocorticosteroid hormones. J. Clin. Invest. 51 : 000.

11. Hechter, O., M. Solomon, A. Zaffaroni, and G. Pincus. 1953. Transformation of cholesterol and acetate to adrenal cortical hormones. Arch. Biochem. 46: 201.

12. Zilversmit, D. B. 1968. Cholesterol flux in the atherosclerotic plaque. Ann. N.Y. Acad. Sci. 149: 710 .

13. Lang, P. D., and W. Insull, Jr. 1970. Lipid droplets in atherosclerotic fatty streaks of human aorta. J. Clin. Invest. 49 : 1479.

14. Christophe, A., and F. Matthijs. 1967. New method for the determination of the fatty acid pattern of serum lipid classes. Clin. Chim. Acta. 16: 39.

15. Sperry, W. M., and M. Webb. 1950. A revision of the Schoenheimer-Sperry method for cholesterol determination. J. Biol. Chem. 187: 97.

16. Brownell, G. L., M. Berman, and J. S. Robertson. 1968. Nomenclature for tracer kinetics. Int. J. Appl. Radiat. Isotop. 19 : 249.

17. Swann, W. H. 1969. A survey of non-linear optimization technics. FEBS Letters. 2(Suppl.) : S 39.

18. Powell, M. J. D. 1964. An efficient method of finding the minimum of a function of several variables without calculating derivatives. The Computer Journal. 7: 155.

19. Berman, M., and M. Weiss. SAAM manual. National Institute of Arthritis and Metabolic Diseases. Public Health Service Publication No. 1703.

20. King, R. E. 1967. Parametric sensitivity of physiological systems. Prognostic analysis. IEEE Transactions on Bio-Medical Engineering. Vol. BME 14. 209-215.

21. Drucker, W. D., A. Sfikakis, A. J. Borkowski, and N. P. Christy. 1964. On the rate of formation of steroidal glucuronosides in patients with familial and acquired jaundice. J. Clin. Invest. 43: 1952.

22. Burton, R. B., A. Zaffaroni, and E. H. Keutmann. 1951. Paper chromatography of steroids. II. Corticosteroids and related compounds. J. Biol. Chem. 188: 763.

23. Bush, I. E. 1952. Methods of paper chromatography of steroids applicable to the study of steroids in mammalian blood and tissue. Biochem. J. 50: 370.

24. Eberlein, W. R., and A. M. Bongiovanni. 1955. New solvent systems for the resolution of corticosteroids by paper chromatography. Arch. Biochem. 59: 90.

25. Peterson, R. E. 1959. The miscible pool and turnover rate of adrenocortical steroids in man. Recent Progr. Hormone Res. 15 : 231.
26. Baird, D. T., R. Horton, C. Longcope, and J. F. Tait. 1969. Steroid dynamics under steady-state conditions. Recent Progr. Hormone Res. 25: 611.

27. Zilversmit, D. B. 1960 . The design and analysis of isotope experiments. Amer. J. Med. 29: 832.

28. Shyamala, G., W. J. Lossow, and I. L. Chaikoff. 1965. Esterification of cholesterol and hydrolysis of cholesterol oleate by homogenates of bovine adrenal glands and their subcellular components. Proc. Soc. Exp. Biol. Med. 118: 138.

29. Shyamala, G., W. J. Lossow, and I. L. Chaikoff. 1966. Esterifications of cholesterol by rat adrenal gland homogenates and subcellular components. Biochim. Biophys. Acta. 116: 543.

30. Goodman, DeW. S. 1964. The in vivo turnover of individual cholesterol esters in human plasma lipoproteins. J. Clin. Invest. 43: 2026.

31. Chobanian, A. V., and W. Hollander. 1962. Body cholesterol metabolism in man. I. The equilibration of serum and tissue cholesterol. J. Clin. Invest. 41: 1732.

32. Glomset, J. A. 1968. Review: the plasma lecithin-cholesteryl transferase reaction. J. Lipid Res. 9: 155.

33. Schumaker, V. N., and G. H. Adams. 1969. Circulating lipoproteins. Ann. Review Bioçhem. 38: 113.

34. Brot, N., W. J. Lossow, and I. L. Chaikoff. 1964. In vitro uptake and hydrolysis, by rat tissues, of cholesterol esters of a very low density, chyle lipoprotein fraction. J. Lipid Res. 5 : 63.

35. Moore, J. H., and D. H. Williams. 1966. Studies on the cholesterol esters of the adrenal glands and other tissues of the rabbit. Biochem. Biophys. Acta. 125: 352.

36. Dailey, R. C., L. Swell, and C. R. Treadwell. 1962. Utilization of free and esterified cholesterol- $4-{ }^{14} \mathrm{C}$ for corticoid biosynthesis by hog adrenal homogenates. Proc. Soc. Exp. Biol. Med. 110: 571.

37. Dailey, R. C., L. Swell, and C. R. Treadwell. 1963. Hydrolysis and utilization of cholesterol esters for steroid synthesis by canine adrenal homogenates. Arch. Biochem. Biophys. 100: 360.

38. Fawcett, D. W., J. A. Long, and A. L. Jones. 1969. The ultra-structure of endocrine glands. Recent Progr. Hormone Res. 25 : 315.

39. Savard, K., J. M. Marsh, and B. F. Rice. 1965. Gonadotropins and ovarian steroidigenesis. Recent Progr. Hormone Res. 21 : 285.

40. Sayers, G., M. A. Sayers, E. G. Fry, A. White, and C. N. H. Long. 1943-1944. The effect of the adrenotrophic hormone of the anterior pituitary on the cholesterol content of the adrenals. Yale J. Biol. Med. 16: 361.

41. Riley, C. 1963. Lipids of human adrenal. Biochem. J. 87: 500 .

42. Young, D. G., and P. F. Hall. 1969. The side-chain cleavage of cholesterol and cholesterol sulfate by enzymes from bovine adrenocortical mitochondria. Biochemistry. $8: 2987$.

43. Drayer, N. M., K. D. Roberts, L. Bandi, and S. Lieberman. 1964. The isolation of cholesterol sulfate from bovine adrenals. J. Biol. Chem. 239: PC 3112.

44. Ney, R. L., R. N. Dexter, W. W. Davis, and L. D. Garren. 1967. A study of the mechanisms by which adrenocorticotrophic hormone maintains adrenal steroidogenic responsiveness. J. Clin. Invest. 46: 1916. 
45. Davis, W. W., and L. D. Garren. 1966. Evidence for the stimulation by adrenocorticotrophic hormone of the conversion of cholesterol esters to cholesterol in the adrenal in vivo. Biochem. Biophys. Res. Comm. 24: 805.

46. Davis, W. W., and L. D. Garren. 1968. On the mechanism of action of adrenocorticotrophic hormone. The inhibitory site of cycloheximide in the pathway of steroid biosynthesis. J. Biol. Chem. 243: 5153.

47. Dexter, R. N., L. M. Fishman, R. L. Ney, and G. W. Liddle. 1967. An effect of adrenocorticotrophic hormone on adrenal cholesterol accumulation. Endocrinology. 81 : 1185.

48. Dobbie, J. W., and T. Symington. 1966. The human adrenal gland with special reference to the vasculature. J. Endocrinol. 34 : 479.
49. Urquhart, J. 1965. Adrenal blood flow and adrenocortical response to corticotropin. Amer. J. Physiol. 209: 1162.

50. Delcroix, C., and F. Cantrenne. 1968. Contribution au choix des paramètres d'un modèle biologique. In Radioaktive Isotope in Klinik und Forscheing. Urban und Schwarzenberg, München. 241.

51. Sheppard, C. W. 1962. Basic principles of the tracer method. John Wiley \& Sons, Inc., New York. 60.

52. King, R. E. 1967. Diagnostic analysis of physiological systems. In 20th Annual Conference of Engineering in Medicine and Biology. 8.

53. Tomovic, R. 1963. Sensitivity analysis of dynamic systems. McGraw-Hill, Inc., New York. 